\title{
BMJ Open Overview of the uptake and implementation of non-medical prescribing in Wales: a national survey
}

\author{
Molly Courtenay, ${ }^{1}$ Riyad Khanfer, ${ }^{1}$ Gail Harries-Huntly, ${ }^{2}$ Rhain Deslandes, ${ }^{3}$ \\ David Gillespie, ${ }^{4}$ Karen Hodson, ${ }^{3}$ Gary Morris, ${ }^{1,5}$ Anthony Pritchard, ${ }^{1}$ \\ Elizabeth Williams ${ }^{1}$
}

To cite: Courtenay M, Khanfer R, Harries-Huntly G, et al. Overview of the uptake and implementation of nonmedical prescribing in Wales: a national survey. BMJ Open 2017;7:e015313. doi:10.1136/ bmjopen-2016-015313

- Prepublication history for this paper is available online. To view these files please visit the journal online (http://dx.doi. org/10.1136/bmjopen-2016015313).

Received 30 November 2016 Revised 2 August 2017 Accepted 2 August 2017

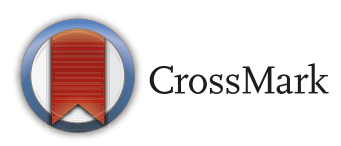

${ }^{1}$ School of Healthcare Sciences, College of Biomedical and Life Sciences, Cardiff University, Cardiff, UK

${ }^{2}$ Department of Workforce Education and Department Service, NHS Wales Shared Services Partnership, Cardiff, UK ${ }^{3}$ Cardiff School of Pharmacy and Pharmaceutical Sciences, Cardiff University, Cardiff, UK ${ }^{4}$ South East Wales Trials Unit, Centre for Trials Research, Cardiff University, Cardiff, UK ${ }^{5}$ Hywel Dda University Health Board, Carmarthen, UK

Correspondence to Dr Molly Courtenay; courtenaym@cardiff.ac.uk

\section{ABSTRACT}

Objectives To identify (1) the non-medical healthcare professionals in Wales qualified to prescribe medicines (including job title, employer, where the prescribing qualification is used, care setting and service provided); (2) the mode of prescribing used by these healthcare professionals, the frequency with which medicines are prescribed and the different ways in which the prescribing qualification is used; and (3) the safety and clinical governance systems within which these healthcare professionals practise.

Design National questionnaire survey.

Setting All three National Health Service (NHS) Trusts and seven Health Boards $(\mathrm{HB})$ in Wales.

Participants Non-medical prescribers.

Results 379 (63\%) participants responded to the survey. Most of these prescribers (41.1\%) were specialist nurses who work in a variety of healthcare settings (primarily in secondary care) within each HB/NHS Trust, and regularly use independent prescribing to prescribe for a broad range of conditions. Nearly a quarter of the sample $(22 \%)$ reported that prior to undertaking the prescribing programme, they had completed master's level specialist training and $65.5 \%$ had 5 years qualified experience. Over half $(55.8 \%)$ reported that there were plans to increase non-medical prescriber numbers within the team in which they worked. Only $7.1 \%$ reported they did not prescribe and the median number of items prescribed per week was between 21 and 30 . Nearly all $(87.8 \%)$ of the sample reported that they perceived prescribing to have ensured better use of their skills and $91.5 \%$ indicated that they believed it had improved the quality of care they were able to provide.

Conclusion Non-medical prescribing has been implemented across the whole of Wales; however, its uptake within HBs and NHS Trusts has been inconsistent, and it has not been considered across all services, particularly those in primary care. Opportunities therefore exist to share learning across organisations.

\section{INTRODUCTION}

The last two decades have seen significant advances in the role and function of non-medical healthcare professionals (nurses, pharmacists and allied health professionals (AHPs)) who have developed
Strengths and limitations of this study

- This is the first national survey of non-medical prescribing in Wales.

- Although data presented are the opinions of participants who completed the survey and, as such, may not represent the general population of nonmedical prescribers (NMP) in Wales, given the high response rate and the similar demographic profile of our sample to previous UK national evaluations of non-medical prescribing, we are confident that a non-response bias was minimal.

- The data collected were self-reported, and so information such as number of items prescribed is therefore likely to be estimated; however, our findings are similar to those of previous UK nonmedical prescribing national evaluations which indicates that this was not overly problematic.

- Only 606 NMPs (out of the 806 to whom the link to the online questionnaire was sent) acknowledged the email as delivered and read and this shortfall could have resulted in the proportion of NMPs working in primary care being lower than expected; however, information from the non-medical prescribing course commissioner for Wales (Workforce, Education and Development Service) identified that 166 of these individuals were based in secondary care and 31 in primary care (3 were unknown); we are therefore confident that this did not result in this shortfall.

innovative and extended roles in a number of countries including legislative authority to prescribe. Although non-medical healthcare professionals can prescribe in several countries including the UK, the USA, New Zealand, Netherlands, Ireland, Australia, Canada and Sweden, ${ }^{1-4}$ their scope of practice varies depending on the protocols and formularies in place. Drivers for this role include quicker and more efficient access to medicines, better use of healthcare professionals' knowledge and skills, the need to reduce the workload of doctors and address doctor shortages, and the development of advanced practitioner roles. ${ }^{1}$ 
No other country in the world has such extended non-medical prescribing rights as the UK. ${ }^{1}$ The first group of non-medical prescribers (NMPs) in the UK to be provided with the capacity to prescribe was community nurse practitioners. These nurses are able to prescribe from a limited list of medicines. ${ }^{5}$ Independent prescribing rights were extended in 2001 to include any first level registered nurse, with 3 years qualified experience, ${ }^{6}$ and in 2006 to include registered pharmacists with 2 years qualified experience. ${ }^{7}$ Within the last 3 years, registered AHPs (ie, physiotherapists, podiatrists/chiropodists, radiographers ${ }^{8}$ ) and optometrists, ${ }^{9}$ normally with 3 years relevant postqualification experience, have also been provided with independent prescribing capability.

Apart from some restrictions around independent prescribing of controlled drugs (CDs) by AHPs, these non-medical healthcare professionals are able to prescribe any medicine within their area of competence independently, that is, they are responsible for the assessment, diagnosis and decisions about the clinical management required in patients with diagnosed or undiagnosed conditions. They are also able to prescribe as a supplementary prescriber, ${ }^{10}$ which involves a written agreement, between the patient, doctor and supplementary prescriber, on a list of medicines from which the supplementary prescriber is able to prescribe. Supplementary prescribing is designed for the management of long-term conditions where patients have a confirmed diagnosis.

The number of NMPs in the UK has steadily increased over the last 5 years, ${ }^{11}$ and will continue to do so in order to fulfil the workforce needs of the National Health Service (NHS). ${ }^{12-14}$ The steady increase in these numbers has been facilitated by the model of prescribing training, typically $3-6$ months in duration, which is funded by the government and only requires applicants to be at degree level. This contrasts with some countries (eg, the USA, Canada and Australia), where training to prescribe, also available to registered nurses, is at master's level and is a component of the advanced nurse practitioner programme, usually 2 years in length. ${ }^{15}$

There are currently approximately 35000 community nurse practitioner prescribers, 30000 nurse independent/supplementary prescribers, 3000 pharmacist independent/supplementary prescribers and 600 AHPs and optometrists, with prescribing capability. ${ }^{11}$ Most of the available evidence relates to nurse and pharmacist prescribers and it is evident from this research that the majority of these prescribers work in general practice (GP) in primary care. ${ }^{16} 17$ Prescribing by these healthcare professionals is safe and clinically appropriate. ${ }^{17}$ Stakeholders are generally satisfied with non-medical prescribing, ${ }^{18-23}$ and report that it increases the accessibility and flexibility of services. ${ }^{23-25} \mathrm{~A}$ number of benefits for NMPs themselves have also been reported including greater autonomy and increased job satisfaction, more time with patients and the ability to provide a complete episode of care, increased self-confidence, time and cost savings. ${ }^{26-28}$ Although the numbers of NMPs continue to grow, ${ }^{29}$ there are, however, wide variations in these numbers both within and across organisations, ${ }^{16} 172930$ resulting in an inequality of service. Barriers to the implementation and continuation of non-medical prescribing have also been reported including restrictions of local arrangements (such as the inability to computer generate prescriptions), lack of peer support, organisational and policy restrictions, and difficulties in fulfilling continuing professional development (CPD) needs. ${ }^{16}{ }^{31}$ Inconsistencies in the clinical governance systems within which NMPs work have also been identified, ${ }^{16}$ and such variations can influence prescribing activity and its ongoing use.

NHSWales delivers services through seven Health Boards (HBs) and three NHS Trusts with an all Wales focus. HBs include Aneurin Bevan University Health Board, Abertawe Bro Morgannwg University Health Board, Cardiff and Vale University Health Board, Hywel Dda University Health Board, Cwm Taf University Health Board, Betsi Cadwaladr University Health Board (BCUHB) and Powys Teaching University Health Board. NHS Trusts include the Welsh Ambulance Service, Velindre NHS Trust and Public Health Wales. Primary care in Wales is provided by general practitioners and other healthcare professionals in health centres and services across Wales. Secondary care is delivered through the hospital and ambulance services. Tertiary care is provided by hospitals which treat particular types of illness such as cancer. Community care services are usually provided in partnership with local social services and delivered to patients in their homes. There is no evidence available with regard to the extent to which non-medical prescribing has been implemented within HBs and NHS Trusts in Wales. The aim of this study was to provide an overview of the uptake and implementation of non-medical prescribing in Wales. The specific objectives were to identify:

- the non-medical healthcare professionals qualified to prescribe medicines including job title, employer, where the prescribing qualification was used, care setting, service provided, years qualified as a prescriber and specialist training;

- the mode of prescribing used by these healthcare professionals, the frequency with which they prescribe and the different ways in which the prescribing qualification is used;

- the safety and clinical governance systems within which these healthcare professionals practise.

\section{METHODS}

Design

A national online questionnaire survey.

\section{Participants}

NMPs working within all HBs and NHS Trusts within Wales.

\section{Questionnaire}

Bristol Online Survey-a tool for creating web surveyswas used to develop an online questionnaire. The 


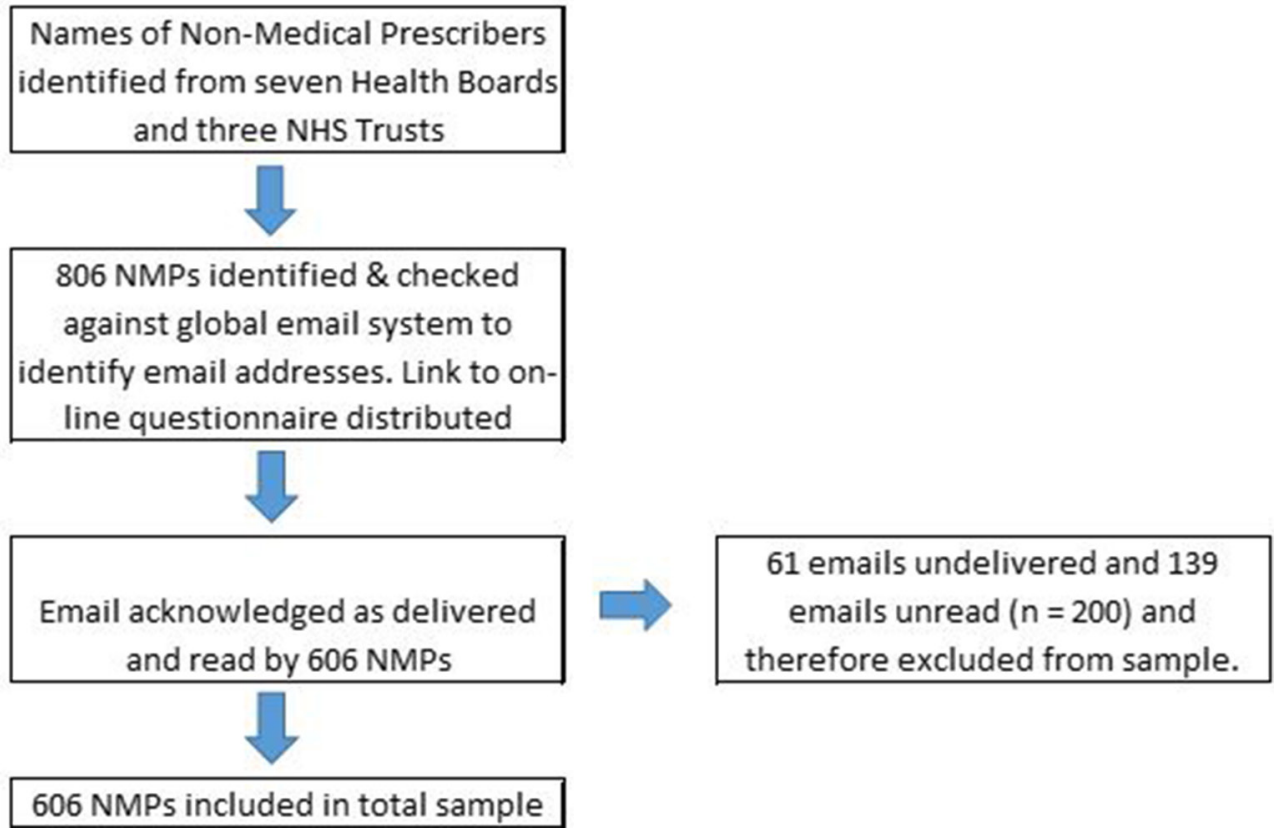

Figure 1 Identification of sample. NHS, National Health Service; NMP, non-medical prescriber.

questionnaire used previously in England, ${ }^{16}$ and revised in order that it was appropriate to deliver to NMPs working in NHS Wales, was divided into four sections. Questions were mainly fixed choice with room for open-ended comment. Section 1 collected general demographic information including job title, job band (ie, a higher band/grade reflects salary/managerial responsibility/ clinical expertise; band $5 / \mathrm{E}=$ lower band/grade; band 8 or $9 /$ I=higher band/grade), employer, HB/NHS Trust in which the respondent was based, where the prescribing qualification was being used, contracted hours per week, age range, highest level of academic qualification, care setting, type of service provided (ie, hospital inpatient, hospital outpatient, community clinic, GP service, independent sector, Her Majesty's Prison Service, community/intermediate care, out-of-hours), number of NMPs in the team and factors that hampered expanding these numbers. Section 2 asked questions specific to participants' prescribing background including the type of prescribing qualification held, number of years qualified as a prescriber, number of years' experience in main area of prescribing practice prior to undertaking the prescribing programme, and specialist training undertaken prior to becoming a prescriber. Section 3 comprised questions about prescribing practice. Questions included whether participants prescribed, the method of prescribing currently used, the number of items prescribed per week and training experience since qualifying as a prescriber. A separate question also asked participants to indicate from a list of 10 statements the different ways in which they specifically used the prescribing qualification including the use of hospital medication charts, WP10/ WPH10 prescriptions (ie, prescription forms that can be dispensed on the NHS by prescribers), private prescriptions, making recommendations to another provider (ie, even though a prescription is not produced, the same clinical decision making is undertaken) and remote prescribing. Participants were also asked in which therapeutic areas they prescribed. The final section focused on clinical governance. Participants were asked to identify (from a list of 11 statements) the clinical governance systems in place within their organisation. This included such statements as whether or not participants' employer had an up-to-date NMP policy in place, whether they had access to CPD and whether they had provided their employer with a specimen signature enabling pharmacists to check whether dispensed prescriptions are bona fide. They were also asked to indicate (using a 5-point Likert scale) from a list of 10 statements their experiences after the prescribing programme, including the extent to which they perceived prescribing had ensured better use of their skills, whether it had improved the quality of care they were able to provide, if peers/team members were supportive of the prescribing role, if they were able to prescribe all the medicines they needed in order to do their job, if they received an appropriate level of support from their employer, medical practitioner/other clinician, if they were limited in their prescribing practice and reasons why. At the end of the questionnaire, participants were also asked to supply their contact details if they were interested in taking part in future research.

\section{Data collection}

Directors of the seven HBs and three NHS Trusts in Wales were contacted by the Workforce, Education and Development Service (WEDS), the non-medical prescribing course commissioner for Wales, and asked for the names of NMPs within their HB/NHS Trust. Eight hundred and six NMPs were identified. These names were then checked against the global email system to identify individual 
email addresses, and a link to the online questionnaire was distributed by WEDS to each of the 806 addresses. 'Delivery and Read' receipts were attached. Only 606 of these emails were acknowledged as delivered and read, that is, 61 emails were undelivered and 139 were unread. Therefore, these 200 NMPs were removed from the sample (see figure 1). Data collection took place between March 2016 and June 2016.

\section{Ethical consideration}

Ethical approval for the study was provided by the School of Healthcare Sciences Research Ethics Committee, Cardiff University.

\section{Data analysis}

Microsoft Excel and IBM SPSS V.17 were used for data entry and analysis. Descriptive statistics were used to describe the demographic nature of the sample. Content analysis, ${ }^{32}$ used to analyse free text comments, was undertaken to further explore qualitative findings. This process involved initial identification of commonly occurring themes, representing the range of responses. Themes were then broken down into mutually exclusive and exhaustive categories, and responses were assigned to categories and coded. The frequency of different responses was then counted. This process was performed manually.

\section{RESULTS}

Of the 606 participants who received and read the email containing the link to the survey, $379(63 \%)$ responded.

\section{General demographic information}

The demographic data of the sample are presented in table 1 .

Participants were from all seven HBs and two NHS Trusts, with the highest numbers (129 or $34.3 \%$ ) based in BCUHB. Only 17 (4.5\%) were based in Velindre NHS Trust. Three hundred and twenty-one $(84.7 \%)$ respondents were nurses, the largest majority (156 or $41.5 \%$ ) of whom had specialist roles. Forty-six (12.1\%) were pharmacists, nine $(2.4 \%)$ were AHPs. Most participants (208 or 55.9\%) were aged between 46 and 55 years, 264 $(71.4 \%)$ worked full-time and $226(59.8 \%)$ were a band 7. The majority of nurses ( $\mathrm{n}=288$ or $89 \%$ ), all pharmacists $(n=47$ or $100 \%)$ and all AHPs $(n=9$ or $100 \%)$, were employed by NHS Trust/HB. Master's and PhD qualifications were held by $210(52.4 \%)$ respondents. The numbers of NMPs in healthcare teams varied. The median number of NMPs in healthcare teams was 2 (IQR from 1 to 4 ), and over half of the respondents (202 or 55.8\%) indicated that there were plans to increase these numbers. Factors hampering expanding the numbers of NMPs in teams, identified from free text comments, included: lack of staff $(n=33)$, workload and lack of time $(n=60)$, and lack of funding $(\mathrm{n}=51)$.
Prescribing background

Over three-quarters of participants (307 or $79.5 \%$ ) reported they were qualified nurse independent/supplementary prescribers, $18(4.7 \%)$ of whom indicated they were also qualified community practitioner prescribers, and $47(12.4 \%)$ indicated they were pharmacist independent/supplementary prescribers. Only small numbers (6 or $1.6 \%$ ) were physiotherapist independent/and or supplementary prescribers. Fewer ( 1 or $0.3 \%)$ were podiatrist/chiropodist independent and/or supplementary prescribers, and two $(0.5 \%)$ were radiographer supplementary prescribers (see table 1 ). The majority of participants (280 or $76.2 \%$ ) had been qualified to prescribe for more than 3 years and $243(65.5 \%)$ indicated that they had more than 5 years' experience in their area of practice before undertaking the prescribing programme. One hundred and fifty-one (22\%) reported they had undertaken master's level specialist training in their area of prescribing practice.

\section{Prescribing practice}

Three hundred and twenty-seven $(86.1 \%)$ participants reported that they currently used independent prescribing and $26(6.8 \%)$ reported that they only used supplementary prescribing. Twenty-seven (7.1\%) (including 21 nurses and 6 pharmacists) reported they did not prescribe. Reasons for not prescribing identified from free text comments included role change, that is, no longer a need to prescribe $(n=15)$, a lack of support from employers and managers $(n=8)$, and lack of confidence $(\mathrm{n}=2)$.

The number of items prescribed per week using independent prescribing is described in table 2. Participants $(n=333,87.9 \%)$ reported on their independent prescribing, and the median number of items prescribed per week was 21-30 items (modal group was 1-5 items). Only $67(17.7 \%)$ participants reported on their supplementary prescribing, and the median number of items prescribed per week was 0 item (modal group was also 0 item).

\section{Therapy areas}

The range of therapy areas for which participants prescribed is shown in figure 2.

Areas in which the greatest numbers of nurses reported that they prescribed included pain (121 or $37.1 \%)$, infections (116 or $35.9 \%)$, cardiovascular (105 or $32.6 \%$ ) and minor ailments (82 or $25.4 \%$ ). Greater numbers of pharmacists indicated that they prescribed for anticoagulation (11 or $23.4 \%$ ), pain (8 or $17 \%$ ), cardiovascular (7 or $14.9 \%)$ and gastroenterology (7 or $14.9 \%)$. Pain (5 or $55.5 \%$ ), musculoskeletal ( 4 or $44.4 \%$ ) and wound care ( 4 or $44.4 \%$ ) were the areas in which higher numbers of AHPs reported they prescribed.

\section{Ways in which the prescribing qualification is used}

Prescribers reported that they used a range of methods to use their prescribing qualification (see figure 3); the 
Table 1 Demographic details

n $\%$

Clinical role

Specialist nurses (clinical nurse specialists, specialist nurse practitioners, nurse clinician, paediatric specialist $156 \quad 41.5$ nurse)

Community nurses (community matron, children's community nurse, health visitor, district nurse, school nurse) 18

General practice nurses (practice nurses and nurse practitioners)

Senior clinical nurses (nurse consultant, lead nurse, ward manager, sister, charge nurse, team leader, modern $38 \quad 10.1$ matron)

Mental health nurses (community psychiatric nurse, primary care link worker, liaison nurse, clinical coordinator) 82.1

Nurse managers (director of nursing, service lead, information manager)

$13 \quad 3.5$

Pharmacists (team leader/manager, senior clinical pharmacist, senior pharmacist (care homes, elderly,

transplant), education and training pharmacist, community pharmacist, practice support pharmacist)

\begin{tabular}{lr} 
Physiotherapists & 4.1 \\
Podiatrists/chiropodists & 0.3 \\
Radiographers & 0.5 \\
Optometrists & 0.0 \\
Other & 0 \\
\hline
\end{tabular}

\section{HB/NHS Trust based}

Aneurin Bevan University Health Board

Abertawe Bro Morgannwg University Health Board

Cardiff and Vale University Health Board

Hywel Dda University Health Board

Cwm Taf University Health Board

Betsi Cadwaladr University Health Board

Powys Teaching University Health Board

$18 \quad 4.8$

Welsh Ambulance Service Trust

Velindre NHS Trust

$0 \quad 0.0$

Public Health Wales

$17 \quad 4.5$

Where prescribing qualification used

General practice

10.3

NHS Trust

Health Board

Care setting

Primary

$191 \quad 48.4$

Secondary

Primary and secondary

Community

$48 \quad 11.5$

Tertiary

$68 \quad 16.3$

Service provided

NHS hospital inpatient

$30 \quad 7.2$

NHS hospital outpatient

NHS community clinic

$193 \quad 32.9$

General practice service

$46 \quad 7.8$

Independent sector

$56 \quad 9.5$

Her Majesty's Prison Service

30.5

Community/intermediate care

$3 \quad 0.5$

Out-of-hours

$\begin{array}{ll}63 & 10.7\end{array}$


Table 1 Continued

n $\%$

Highest level of academic qualification

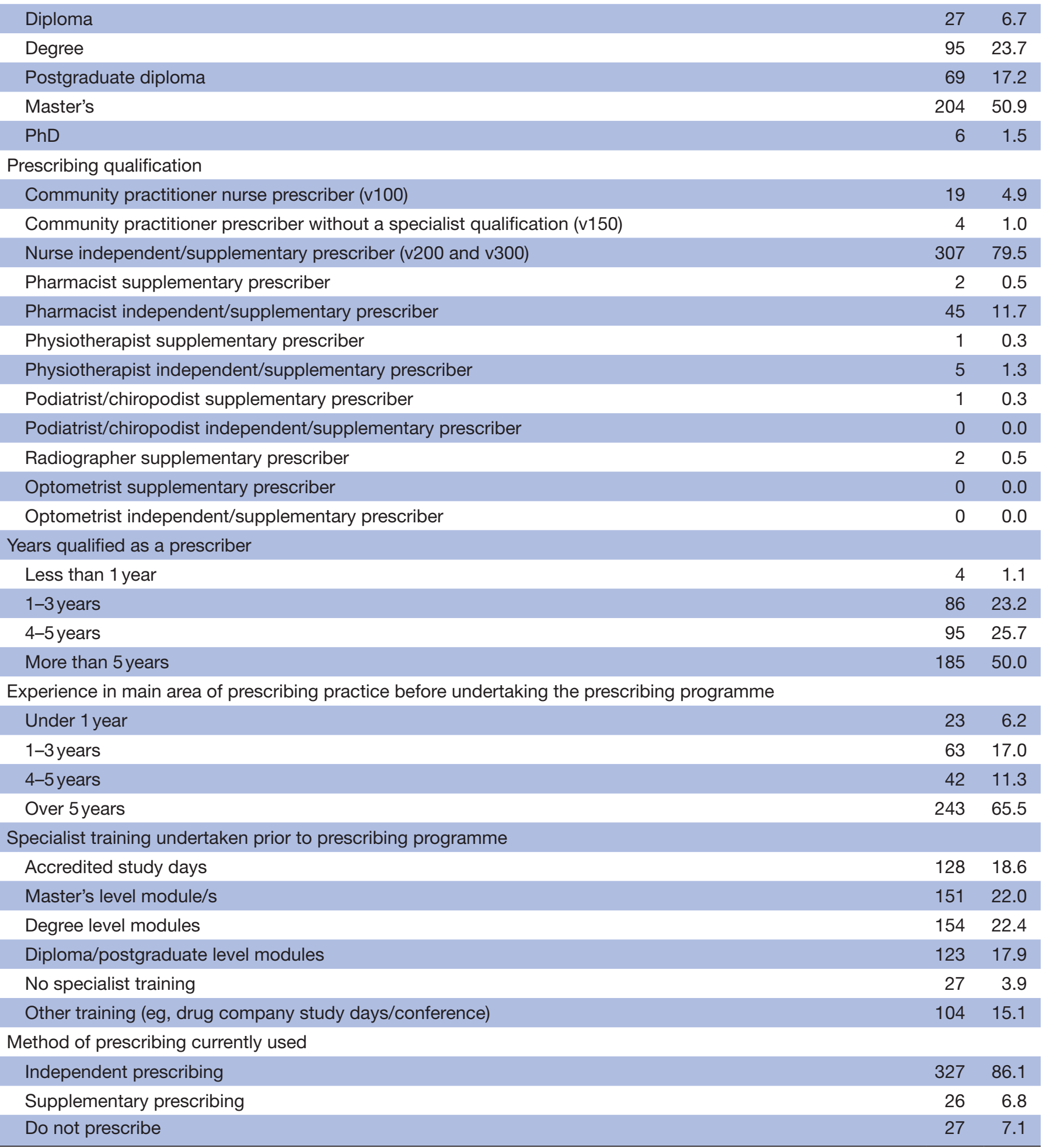

Owing to missing data from participants who chose not to disclose demographic information the percentages do not always equal $100 \%$. 'Where prescribing qualification used' adds up to more than $100 \%$ as some participants were prescribing in more than one area. Each of the categories under 'Clinical role' is mutually exclusive.

HB, Health Board; NHS, National Health Service. 
Table 2 Number of items prescribed in a typical week using independent prescribing

\begin{tabular}{|c|c|c|c|c|c|}
\hline \multicolumn{2}{|c|}{ Nurses } & \multicolumn{2}{|c|}{ Pharmacists } & \multicolumn{2}{|r|}{ AHPs } \\
\hline $\mathbf{n}$ & $\%$ & n & $\%$ & $\mathbf{n}$ & $\%$ \\
\hline
\end{tabular}

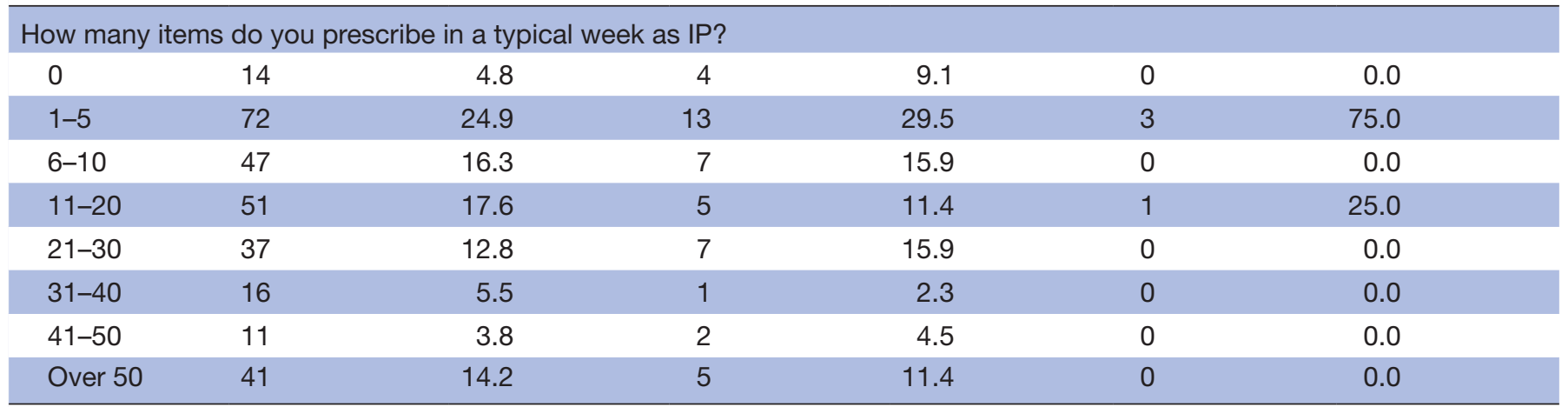

AHP, allied health professional; IP, independent prescribing.

most frequently reported by $20 \%$ of nurses and $25 \%$ of pharmacists included prescribing via hospital medication charts. Other methods reported by nurses included issuing private prescriptions to patients (3 or $0.9 \%$ ) and making recommendations via letter/email or telephone call to GP for medicines to be prescribed (35 or 10\%). A narrower range of methods was reported by pharmacists and included remote prescribing by telephone, email or fax ( 1 or $2.1 \%$ ) and making recommendations via patient's hospital notes for medicines to be prescribed (3 or $6.4 \%$ ). The few methods reported by AHPs included making recommendations for patients to buy over-thecounter medicines (1 or $11.1 \%$ ).

Governance and support

Some systems (such as the provision of a specimen signature, and agreed scope of practice) were reported to be in place by a high number of prescribers (see figure 4 ).
However, only a small proportion of nurses (44 or $13 \%$ ) reported they were able to monitor/access their own prescribing data, were provided with regular data to monitor their own prescribing practice (99 or 30\%) or were involved in the development of local formularies and guidance (126 or 39\%). Similarly, only 20 (42\%) of pharmacists reported they had access to their prescribing data.

\section{Experience after the prescribing programme}

High numbers of respondents (333 or $87.8 \%$ ) reported that they perceived prescribing to have ensured better use of their skills, and $347(91.5 \%)$ believed that the ability to prescribe had improved the quality of care they were able to provide. Three hundred and forty-seven $(91.5 \%)$ indicated that peers/team members were supportive of the prescribing role, and 308 or $81.2 \%$ indicated that they were able to prescribe all the medicines they needed

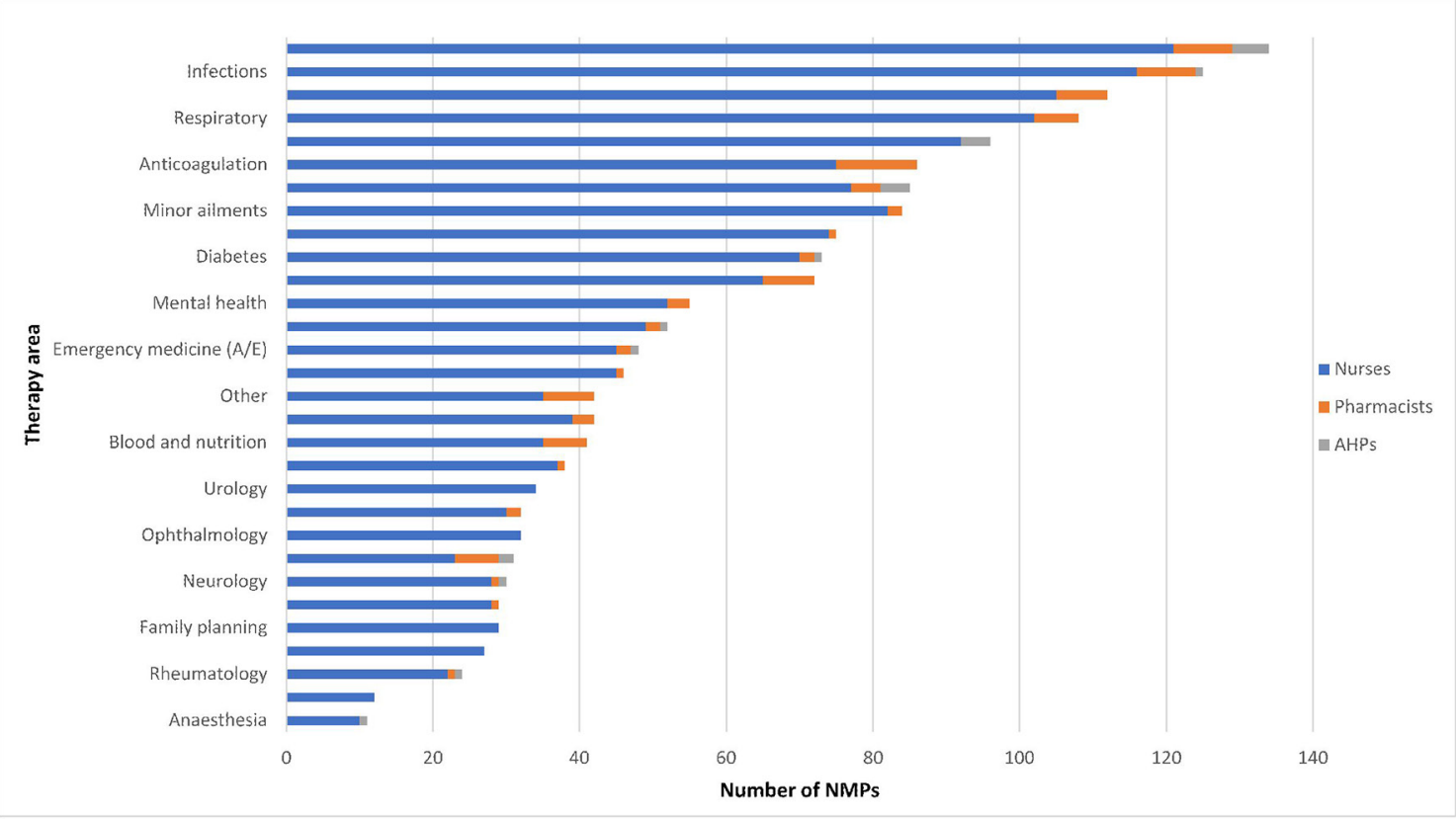

Figure 2 Therapy areas in which NMPs prescribed. AHP, allied health professional; NMP, non-medical prescriber. 


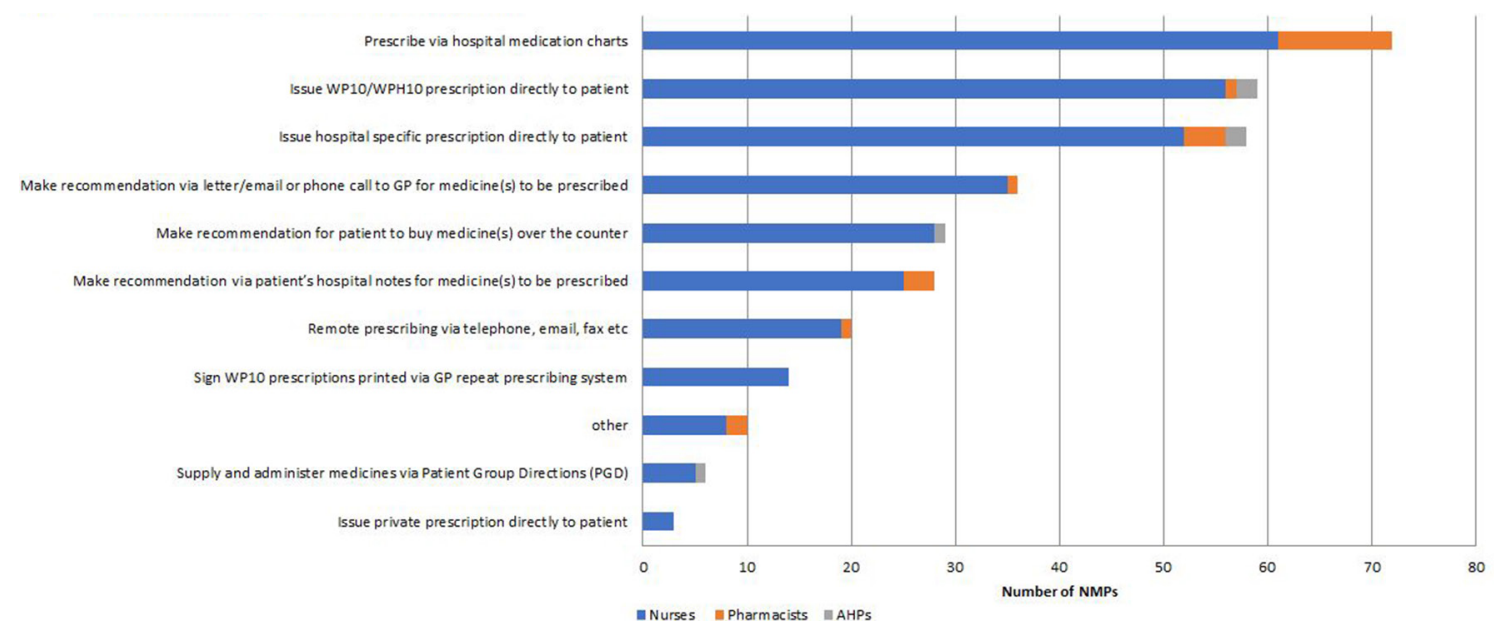

Figure 3 Ways in which the prescribing qualification was used. AHP, allied health professional; GP, general practice; NMP, nonmedical prescriber.

in order to do their job. However, 67 (17.7\%) reported that they did not receive an appropriate level of support from their employer and $83(21.9 \%)$ indicated that they did not receive continued support from a medical practitioner/other clinician. Fifty-eight (15.3\%) reported that they were limited in their prescribing practice. Reasons identified from free text comments included role change, that is, no longer a need to prescribe $(n=11)$, a lack of support from employers, managers and senior team members $(n=8)$, legislative restrictions around CDs $(n=7)$, a lack of prescription pad $(n=6)$ and local formulary restrictions $(\mathrm{n}=5)$.

\section{DISCUSSION}

\section{Statement of principal findings}

NMPs in Wales are primarily specialist nurses who work in a variety of healthcare settings and regularly use independent prescribing to issue prescriptions directly to patients and prescribe via hospital medication charts for a broad range of conditions. Participants reported that prescribing made better use of their skills, and improved the quality of care they were able to provide. Although non-medical prescribing has been implemented across the whole of Wales, its uptake within HBs and NHS Trusts has been inconsistent, and has been primarily implemented within secondary care organisations.

\section{Strengths and weaknesses}

This is the first national study to provide detailed information about the uptake and implementation of non-medical prescribing in Wales. Data presented in this paper are the opinions of subjects who accepted the invitation to participate in the study and as such, may not represent the general population of NMPs. However, given the high response rate and the similar demographic profile

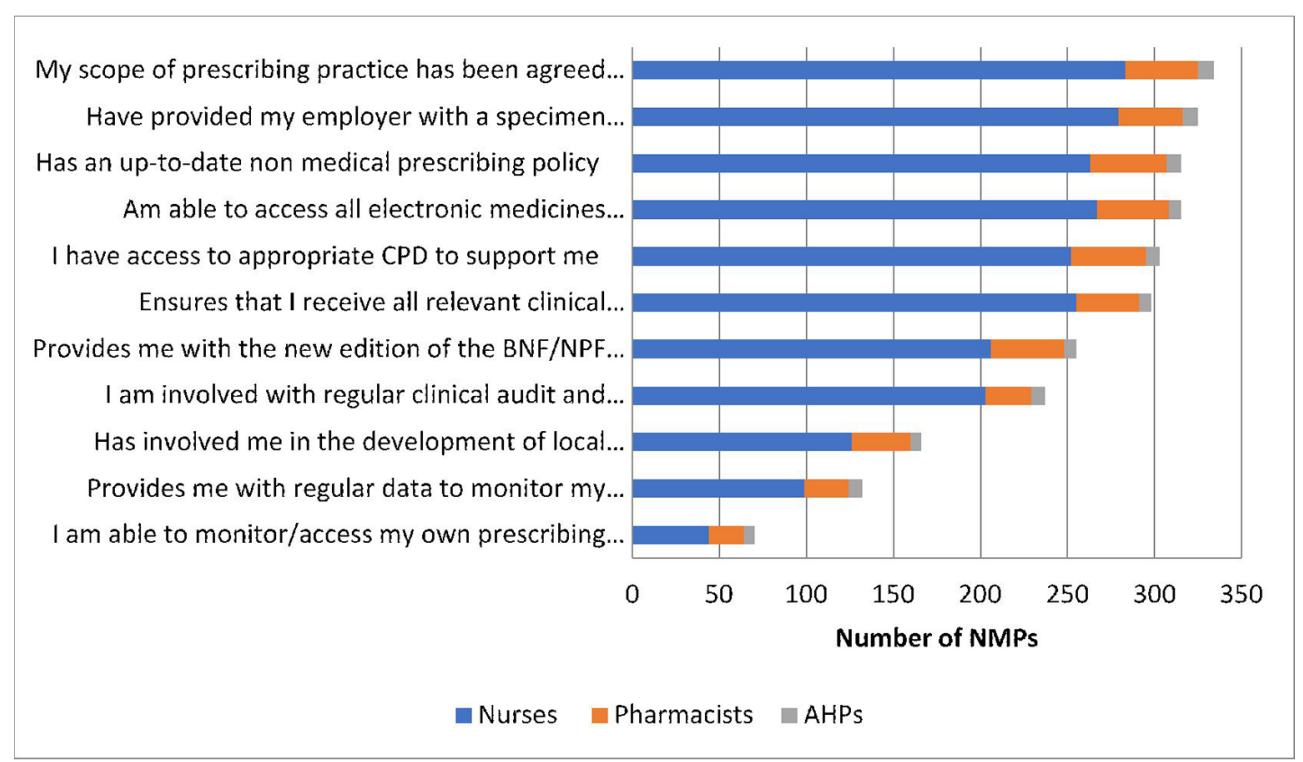

Figure 4 Safety and clinical governance systems in place. AHP, allied health professional; CPD, continuing professional development; NMP, non-medical prescriber. 
of our sample (including the ratio of nurse, pharmacist and AHP prescribers) to previous UK national evaluations of non-medical prescribing, ${ }^{17}$ we are confident that a non-response bias was minimal and that our findings present an accurate picture of this population. Given the data collected were self-reported, information such as number of items prescribed is likely to have been estimated. However, the results of previous UK NMP evaluations ${ }^{16}$ are comparable suggesting that this was not overly problematic. Although 379 (63\%) participants responded, this represents less than half of the population of the 806 NMPs that were originally identified by directors of HBs and NHS Trusts as those working in Wales. Furthermore, as the proportion of NMPs working in primary care is lower than that reported in other UK national surveys, it is possible that this could have been a result of this shortfall. However, information from the non-medical prescribing course commissioner for Wales (WEDS) identified that of the 200 emails undelivered/ unread, 166 of these individuals were based in secondary care and 31 in primary care; we are therefore confident that this did not result in this shortfall.

\section{Comparison with other studies}

NMPs in Wales are primarily specialist nurses, employed by all NHS Trusts/HBs, who prescribe in-hospital inpatient and outpatient services. In line with the findings of previous UK national research, ${ }^{17}$ the uptake of non-medical prescribing by HBs/NHS Trusts has been inconsistent. However, in contrast to our finding that most NMPs were based in secondary care, the results of these studies, and other international evidence, ${ }^{1-4}$ indicate that NMPs predominantly work in primary care.

Similar to previous research, ${ }^{16} 17$ over three-quarters of our sample had over 4 years' experience in their area of prescribing practice prior to undertaking training to prescribe and around two-thirds held a diploma/degree/ master's specialist qualification. Although prescribing rates varied among different groups, aligned with previous evidence, ${ }^{16} 17$ nearly all respondents reported they prescribed; the main reason given for not prescribing being no longer working in a role that required this activity.

In line with findings of a metasynthesis analysis of the nurse prescribing literature, ${ }^{33}$ a lack of funding to support the prescribing role was identified as a barrier to expanding NMP numbers. NMPs reported that they prescribed independently across a broad range of therapeutic areas, and consistent with non-medical prescribing research, ${ }^{16} 173435$ greater numbers of nurses indicated they prescribed for infections, higher numbers of pharmacists indicated they prescribed for pain, and musculoskeletal conditions were those for which larger numbers of AHPs prescribed. Supplementary prescribing was used infrequently and this has been reported previously. ${ }^{16}$

As well as issuing prescriptions directly to patients and prescribing via hospital medication charts, NMPs reported they used their prescribing qualification to undertake a range of other activities including making recommendations via letter/email or telephone call to GP for medicines to be prescribed, remote prescribing by telephone, email or fax, and making recommendations via patient's hospital notes. This is in line with earlier evidence. ${ }^{16}$

For the most part, clinical governance arrangements were reported to be working, with the exception of the ability to obtain prescribing data and monitor or audit prescribing activity. This has been reported previously. ${ }^{16}$

\section{Meaning of the study: possible explanations and implications for clinicians and policymakers}

The wide variance in non-medical prescribing, and particularly the higher proportion of NMPs in secondary care, and its lack of use by primary care organisations, suggests that non-medical prescribing has not been viewed as part of a multidisciplinary whole workforce approach to meet service needs/gaps. However, this seems to be changing, as both the Carter Review in England ${ }^{14}$ and the Workforce Plan for Primary Care in Wales ${ }^{36}$ refer to the role independent prescribers could have in fulfilling the workforce needs of the NHS. Opportunities therefore exist for commissioners of services to share learning across organisations. Where prescribing has been implemented, it is being used and so predicted services are being delivered.

\section{Unanswered questions and future research}

Given the development of primary care services in the UK, ${ }^{1236}$ an important next step would be to explore the lack of use of non-medical prescribing in these services in Wales. Evidence is available that has demonstrated the benefits of non-medical prescribing and its acceptability to patients; however, most of this work has been undertaken in primary care. A useful next step would be to explore its acceptability to patients and benefits in secondary care. Research designed to compare the processes, outcomes and costs of care for patients managed by medical and NMPs would also be valuable for those engaged in service redesign and workforce planning.

\section{CONCLUSION}

Non-medical prescribing has been implemented across the whole of Wales; however, its uptake within HBs and NHS Trusts has been inconsistent, and it has not been considered across all services, particularly those in primary care. Opportunities therefore exist to share learning across organisations.

Acknowledgements We are grateful to all the NMPs who participated in the research. Without their participation, this work would not have been possible.

Contributors MC made a substantial contribution to the conception and design of the work, the acquisition and interpretation of data, and drafting of the work. RK made a substantial contribution to the design of the work, and acquisition, analysis and interpretation of data. GHH made a substantial contribution to the design of the work, and acquisition and interpretation of data. RD, KH, GM, AP and EW made a substantial contribution to the design of the work and the interpretation of data. DG made a substantial contribution to the analysis and interpretation of data. All authors critically revised drafts of the work and approved the final version to be published and agree to be accountable for all aspects of the work in ensuring 
that questions related to the accuracy or integrity of any part of the work are appropriately investigated and resolved.

Competing interests None declared.

Patient consent Obtained.

Ethics approval School of Healthcare Sciences Research Ethics Committee, Cardiff University.

Provenance and peer review Not commissioned; externally peer reviewed.

Data sharing statement № additional data available.

Open Access This is an Open Access article distributed in accordance with the Creative Commons Attribution Non Commercial (CC BY-NC 4.0) license, which permits others to distribute, remix, adapt, build upon this work non-commercially, and license their derivative works on different terms, provided the original work is properly cited and the use is non-commercial. See: http://creativecommons.org/ licenses/by-nc/4.0/

(c) Article author(s) (or their employer(s) unless otherwise stated in the text of the article) 2017. All rights reserved. No commercial use is permitted unless otherwise expressly granted.

\section{REFERENCES}

1. Kroezen M, Van Dijk L, Groenewegen PP, et al. Nurse prescribing of medicines in Western European and Aglo-Saxon, countries: a systematic review of the literature. BMC Health Serv Res 2011;127.

2. Pharmacy Council of New Zealand. 2010. http://www. pharmacycouncil.org.nz/prescriber (accessed 19 Feb 2016).

3. Canadian Pharmacist Association. 2016. https://www.pharmacists. ca/pharmacy-in-canada/scope-of-practice-canada/ (Accessed 19 Feb 2016).

4. Controlled drugs and substances act, press release]2012New Classes of Practitioners Regulations SOR/2012-230;146 http:// canadagazette.gc.ca/rp-pr/p2/2012/2012-11-21/html/sor-dors230eng.html2012.

5. NMC. Standards of proficiency for nurse and midwife prescribers. London: NMC, 2006.

6. DoH. Patients to get quicker access to medicines (Press Release). London: $\mathrm{DH}, 2001$.

7. DoH. Improving patient's access to medicines: A guide to implementing nurse and pharmacist independent prescribing within the NHS in England. London: DoH, 2006.

8. Healthcare Professions Council www.hpc-uk.org/aboutregistration/ medicinesandprescribing

9. DoH: Optometrists to get independent prescribing rights (Press Release). London: DoH, 2007.

10. DoH: Supplementary Prescribing. London: DH, 2005.

11. DoH. personal communication, 2016.

12. NHS Five year forward view. 2014 https://www.england.nhs.uk/ ourwork/futurenhs/

13. Primary Care Workforce Commission. 2016 https://hee.nhs.uk/ourwork/hospitals-primary-community-care/primary-community-care/ primary-care-workforce-commission

14. $\mathrm{DoH}$ Operational productivity and performance in English NHS acute hospitals. London: $\mathrm{DoH}, 2016$.
15. Ball J, Barker G, Buchanan J. Implementing nurse prescribing. Geneva: International Council of Nurses, 2009.

16. Courtenay M, Carey N, Stenner K. An overiew of non medical prescribing across one strategic health authority: a questionnaire survey. BMC Health Serv Res 2012;12:138.

17. Latter S, Blenkinsopp A, Smith A, et al. Evaluation of nurse and pharmacist independent prescribing. University of Southampton and University of Keele on behalf of the DoH 2010.

18. Stewart DC, George J, Bond CM, et al. Exploring patients perspectives of pharmacist supplementary prescribing in Scotland. Pharm World Sci 2008;30:892-7.

19. Cooper R, Anderson C, Avery T, et al. Stakeholders' views of UK nurse and pharmacist supplementary prescribing. J Health Serv Res Policy 2008;13:215-21.

20. Brooks N, Otway C, Rashid C, et al. The patient's view: the benefits and limitations of nurse prescribing. $\mathrm{Br} J$ Community Nurs 2001;6:342-8.

21. Courtenay M, Carey N, Stenner K. Non medical prescribing leads views on their role and the implementation of non medical prescribing from a multi-organisational perspective. BMC Health Serv Res 2011;11:142.

22. Courtenay M, Carey N, Gage H, et al. A comparison of prescribing and non-prescribing nurses in the management of people with diabetes. J Adv Nurs 2015;71.

23. Stenner KL, Courtenay M, Carey N. Consultations between nurse prescribers and patients with diabetes in primary care: A qualitative study of patient views. Int J Nurs Stud 2011;48:37-46.

24. Carey N, Stenner K, Courtenay M. Stakeholder views on the impact of nurse prescribing on dermatology services. J Clin Nurs 2010;19:498-506.

25. Courtenay M, Stenner K, Carey N. An exploration of the practices of nurse prescribers who care for people with diabetes: a case study. Journal of Nursing and Healthcare of Chronic IIIness 2009;1:311-20.

26. Stenner $\mathrm{K}$, Courtenay $\mathrm{M}$. Benefits of nurse prescribing for patients in pain: nurses' views. J Adv Nurs 2008;63:27-35.

27. George J, McCaig D, Bond C. Benefits and challenges of prescribing training and implementation: perceptions and experiences of Royal Pharmaceutical of Great Britain Prescribers. Int J Pharm Pract 2007.

28. NHS Health Education North West. Non-medical prescribing (NMP). An economic evaluation 2015.

29. Dobel-Ober D, Brimblecombe N. National survey of nurse prescribing in mental health services; a follow-up 6 years on. J Psychiatr Ment Health Nurs 2016;23:378-86.

30. NPC: A quick guide for commissioner. London: NPC, 2010.

31. Courtenay M, Carey N, Stenner K. Non medical prescribing leads views on their role and the implementation of non medical prescribing from a multi-organisational perspective. BMC Health Serv Res 2011;11:142.

32. Braun V, Clarke V. Using thematic analysis in psychology. Qualitative research in psychology 2006;3:77-101.

33. Stewart $D$, Jebara $T$, Cunningham $S$,et al.Future perspectives on nonmedical prescribing Ther Adv Drug Saf 2017, 8:183-197

34. General Pharmaceutical Council. Prescribers survey report. https:// www.pharmacyregulation (accessed 1 Oct 2016).

35. Carey N, Stenner K, Gage H, et al. Evaluation of physiotherapist and podiatrist independent prescribing, mixing of medicines, and prescribing of controlled drugs: Policy Research Programme, DoH, 2016.

36. Welsh Government. Our plan for a primary care service for wales up to 2018. Welsh Government 2014. 